\title{
Semantic codes are not used in integrating information across eye fixations in reading: Evidence from fluent Spanish-English bilinguals
}

\author{
JEANETTE ALTARRIBA \\ University at Albany, State University of New York, Albany, New York \\ and \\ GRETCHEN KAMBE, ALEXANDER POLLATSEK, and KEITH RAYNER \\ University of Massachusetts, Amherst, Massachusetts
}

\begin{abstract}
The question of whether meaning can be extracted from unidentified parafoveal words was examined using fluent Spanish-English bilinguals. In Experiment 1, subjects fixated on a central cross, and a preview word was presented to the right of fixation in parafoveal vision. During the saccade to the parafoveal preview word, the preview was replaced by the target word, which the subject was required to name. In Experiment 2, subjects read sentences containing the target word, and, as in the naming task, a preview word was replaced by the target word when the subject's saccade crossed a boundary location. In both experiments, preview words were identical to the target word, translations, orthographic controls for the translations, or unrelated words in the opposite language. In both experiments, the preview benefit from the translation conditions was no greater than would be predicted by the orthographic similarity of the preview to the target. Hence, the data indicated that subjects obtained no useful semantic information from words seen parafoveally that enabled them to identify them more quickly on the subsequent fixation.
\end{abstract}

During reading, our eyes typically fixate on most of the words in the text (Rayner, 1998). However, short function words and words that are predictable from the preceding context are often skipped (Balota, Pollatsek, \& Rayner, 1985; Binder, Pollatsek, \& Rayner, 1999; Ehrlich \& Rayner, 1981; O'Regan, 1979, 1980; Rayner \& Well, 1996; Schustack, Ehrlich, \& Rayner, 1987; Vitu, 1991). The fact that such words are skipped (i.e., not directly fixated) suggests that they can be identified and processed parafoveally. An interesting corollary is that when predictable words are not skipped, fixation time on them tends to be shorter than on unpredictable words (Balota et al., 1985; Binder et al., 1999; Ehrlich \& Rayner, 1981; Rayner \& Well, 1996; Zola, 1984). This latter finding

The order of authors is alphabetical; this was a totally collaborative effort. The research was supported by Grant HD26765 from the National Institute of Health. The first and second authors were also supported by Training Grant HD07327 from the National Institute of Health awarded to the University of Massachusetts, and the fourth author was supported by Research Scientist Award MH01255 from the National Institute of Mental Health. Experiment 1 was conducted while the first author was a postdoctoral fellow at the University of Massachusetts. Portions of the data from Experiment 1 were presented at the 1996 meeting of the Psychonomic Society, and portions of the data from Experiment 2 were presented at the 2000 meeting of the Midwestern Psychological Association. The authors thank Tom Carr, John Henderson, Albrecht Inhoff, Ken Paap, and an anonymous reviewer for their helpful comments on an earlier version of the article. Correspondence should be addressed to K. Rayner, Department of Psychology, University of Massachusetts, Amherst, MA 01003 (e-mail: rayner@psych.umass.edu). could be explained without recourse to parafoveal processing, since predictability may have an influence only after the word is fixated. However, there is evidence that more information is extracted from the preview word when it is predictable (Balota et al., 1985). This article deals with the type of information readers obtain from unidentified parafoveal words before they fixate them.

There is considerable evidence to indicate that readers obtain useful information from unidentified parafoveal words. Specifically, it has been well documented that there is preview benefit from having a valid preview of a word prior to fixating it (Balota et al., 1985; Balota \& Rayner, 1983; Henderson \& Ferreira, 1990; Inhoff, 1989; Kennison \& Clifton, 1995; Pollatsek, Lesch, Morris, \& Rayner, 1992; Rayner, 1975; Rayner, Well, Pollatsek, \& Bertera, 1982; Schroyens, Vitu, Brysbaert, \& d'Ydewalle, 1999; Sereno \& Rayner, 2000). This preview benefit is typically on the order of 30-50 msec and has been demonstrated using two related paradigms. Both employ eye-contingent display changes (McConkie \& Rayner, 1975) and are variations of what has typically been referred to as the boundary paradigm (introduced by Rayner, 1975, 1978). In the first paradigm (Henderson, Dixon, Petersen, Twilley, \& Ferreira, 1995; Rayner, 1978; Rayner, McConkie, \& Ehrlich, 1978; Rayner, McConkie, \& Zola, 1980), subjects are asked to fixate on a cross, and a word (or nonword) is presented in parafoveal vision. When the subject makes an eye movement toward the initially displayed stimulus, it is replaced by a target word that is typically 
named (although other tasks, such as lexical decision and categorization, have also been used). In the second paradigm (Balota et al., 1985; Kennison \& Clifton, 1995; Rayner, 1975; Sereno \& Rayner, 2000), subjects are engaged in the act of reading, and a single critical target word is initially replaced by another word or by a nonword. When the subject's eye movement crosses over a prespecified invisible boundary location in the text, the initially displayed stimulus is replaced by the target word. It is important to note that, in both paradigms, subjects are unaware of either the parafoveal preview or the display change except for in a few trials in the reading studies when the display change occurred just as the saccade was ending (these trials are removed from the analyses).

In both paradigms, preview benefit is derived by subtracting the time (response time in the first case, and fixation time in the second) when the preview was either identical to the target or related to it in some way from the time when the preview was unrelated to the target. In some conditions, the previews were nonwords, but the target was always a word, and, in the reading experiments, the target word always made sense in context. Although the latter paradigm is more ecologically valid (since subjects are actually silently reading text), it is important to note that virtually identical results have been obtained with the two paradigms, in terms of both the type of information that yields preview benefit and the size of the preview benefit. ${ }^{1}$ Unsurprisingly, the amount of preview benefit that is obtained from a parafoveal word is greatest when the preview and target word are identical. However, the fact that preview benefit is also obtained from some types of related previews indicates that partial (or incomplete) word information is obtained from the parafovea (see Rayner, 1998; Rayner \& Pollatsek, 1989). That is, information obtained parafoveally on fixation $n$ is integrated in some way with foveal information processed on fixation $n+1$.

Results of studies using these eye-contingent display change paradigms to assess preview benefit and the type of information integrated across fixations have converged on five general findings. First, integration of information across fixations does not depend on overlapping visual featural information obtained on fixation $n$ with information obtained on fixation $n+1$ (McConkie \& Zola, 1979; Rayner et al., 1980). McConkie and Zola had subjects read text in alternating case, and each time they moved their eyes, the text alternated back and forth from one version of alternating case to another (e.g., $c H a N g E$ shifted to $C h A n G e$ ). Subjects did not notice that the change was taking place, and their reading behavior was not different from that in a control condition in which they read alternated case in which the letters did not change case from fixation to fixation. If low-level visual codes, such as visual features, were important in integrating information across fixations, then the change of features between uppercase and lowercase letters should have disrupted reading. Second, there is orthographic facilitation due to the preview and target sharing letters, especially the first two or three letters (Rayner, 1978;
Rayner et al., 1978; Rayner et al., 1980). But, as we just noted, this facilitation is case independent (McConkie \& Zola, 1979; Rayner et al., 1980), so that a higher level code, such as abstract letter identity, is probably involved. Third, there is facilitation due to the preview and target being phonologically similar (Henderson et al., 1995; Pollatsek et al., 1992). Pollatsek et al. (1992) found that a homophone (beech) of a target word presented in the parafovea facilitated processing of the target word (beach) seen on the next fixation more than did a preview of a word (bench) matched with the homophone in orthographic similarity to the target word. Fourth, morphemic information does not appear to be the source of the preview benefit (Inhoff, 1989; Lima, 1987). Lima used target words with true prefixes (e.g., revive) and words with "pseudoprefixes" (e.g., rescue). If extracting morphemes were a significant part of parafoveal preview benefit, then a larger preview benefit should be observed for prefixed words. However, Lima found equal benefit for the two conditions. Similarly, Inhoff compared preview benefit in reading for true initial morphemes (e.g., cowxxx as a preview for cowboy) and false initial morphemes (e.g., carxxx as a preview for carpet). Although there was preview benefit in both cases (presumably due to the orthographic and phonological overlap between preview and target), there was no difference between the true and false initial morphemes. Finally, it appears that semantic information is not the source of the preview benefit. Since this latter issue was the focus of the present experiments, we shall describe the relevant research in a bit more detail.

Underwood (1985) suggested that semantic preprocessing of unidentified parafoveal words is a relevant factor in integrating information across fixations and aids in the later identification of a word. However, Balota et al. (1985), Rayner, Balota, and Pollatsek (1986), and Rayner et al. (1980) found no empirical support for semantic preprocessing. Rayner et al. (1980) used the boundary naming paradigm described above and presented associates of the target word (matched on word length) as the parafoveal preview. Thus, table was presented as a preview for chair. They found no facilitation from semantically related previews; however, they did find facilitation from orthographically similar previews. Rayner et al. (1986) used the boundary reading paradigm described above. In their experiment, prior to subjects' fixating on a target word (such as tune), the parafoveal preview for that word was orthographically related (turc), semantically related (song), or unrelated (door). When the subjects' eyes crossed the boundary location, the target word replaced the preview word. In a standard priming experiment, the semantically related pairs (song-tune) produced a significant 20-msec facilitation effect in naming. However, in the reading situation, although fixation time on the target word was shorter when the preview was orthographically similar to the target word, there was no difference between the semantically related and unrelated conditions. Thus, Rayner et al. (1986) concluded that readers do not obtain semantic information from unidentified parafoveal words. 
Although the study by Rayner et al. (1986) provided evidence against semantic preprocessing in the parafovea of a word later fixated, semantic priming effects from parafoveal words on simultaneously presented foveal words have been reported in a number of studies (Di Pace, Longoni, \& Zoccolotti, 1991; Fuentes \& Tudela, 1992; Lambert \& Sumich, 1996). In these studies, parafoveally presented prime words purportedly influence the time needed to respond to the foveal target word seen on the same fixation. Besides being a somewhat different paradigm, there are two possible problems associated with these studies. First, there has been no clear pattern of facilitation or interference obtained in the studies: Sometimes the prime yields facilitation effects, sometimes it yields interference effects, and sometimes there is no effect. ${ }^{2}$ The lack of a clear pattern of effects is thus somewhat suspicious. Second, fixation location is often not carefully monitored. This is important, because when fixation location is not ensured by an eye-tracking system, there is evidence that subjects are often not fixating the fixation location specified by the experimenter (Jordan, Patching, \& Milner, 1998; Patching \& Jordan, 1998). Although the authors of these studies have been careful to not generalize their results to reading, these studies nevertheless leave open the possibility that semantic priming effects can be obtained from parafoveal words during reading. ${ }^{3}$

At a theoretical level, it could be argued that there are two reasons that no benefit from semantically related words occurred in the Rayner et al. (1986) study. First, although the semantically related preview words employed by Rayner et al. were good enough associates of the target words to produce a priming effect in a naming task, they may have been less related in meaning to the target words than were homophones (in the phonological domain) or words with similar spelling patterns (in the orthographic domain). Second, the orthographic and phonological difference between the prime and the target word may offset any benefit that might be obtained from semantically related parafoveal words.

The first point is especially important in light of the data accumulated from many priming experiments (Monsell, 1991; Neely, 1991). That is, priming effects appear to be qualitatively different when an identical word is used as a prime (repetition priming) than when a semantic associate is used. Not only are repetition priming effects considerably bigger than semantic priming effects, they are also much longer lasting. Typically, semantic priming effects are very small with one item intervening between prime and target, and they disappear with two intervening items. In contrast, repetition priming effects often survive 10 or more intervening items. Moreover, repetition-like priming effects do not require strict identity. Similar results obtain with morphemically related items (Stanners, Neiser, Hernon, \& Hall, 1979).

In the present experiments, we attempted to remedy these plausible problems in finding evidence for "semantic preprocessing" in the parafovea by using previews that were translations of the target words. We used fluent Spanish-English bilingual subjects as a tool (see also Al- tarriba, Kroll, Sholl, \& Rayner, 1996; Altarriba \& Soltano, 1996) to get at parafoveal semantic processing in reading rather than to study bilingualism per se. We reasoned that, with translations, one had words that were virtually identical in meaning, and, thus, one had the most powerful possible test of whether the meaning of a word seen in the parafovea could be integrated with the meaning of the word when it was subsequently fixated. Although using a translation as a preview is not exactly "repetition priming," it seems like the best possible approximation in the semantic domain.

A concern with this paradigm, of course, is that the meanings of words in the two languages in which the bilinguals are fluent may be in separate storage locations. If so, then a failure to find benefit from a translation preview could be due to the fact that the translation preview and the target are not closely related in the typical bilingual's mental structure. There are several studies, however, that suggest that many words that are translations of each other in the two languages do share something like a lexical representation. For example, Altarriba and Mathis (1997), Gerhand, Deregowski, and McAllister (1995) and Tzelgov, Henik, and Leiser (1990) demonstrated a bilingual "Stroop effect," in which the meaning of a word in one language interferes with naming in the other language. In addition, Caramazza and Brones (1980) found no cost in switching languages for Spanish-English bilinguals while making semantic judgments, which is also consistent with a view that translations share a common mental representation. More recently, Thomas and Allport (2000) came to a similar conclusion using a lexical decision task and argued that prior studies that had found costs of language switching using such tasks had artifacts.

We employed two types of translations in the present experiments. One type was noncognate translations (words that mean virtually the same thing but that are not orthographically or phonologically similar). These allow a strong test of whether semantic codes, without any orthographic or phonological support, can be integrated across saccades. The second type was cognate translations (e.g., cream-crema), in which the translations were orthographically and phonologically similar. These can be used to test whether semantic codes can be integrated across saccades with support from orthographic and phonological codes.

The problem in evaluating the preview effects from these cognate translations is, of course, determining whether any preview benefit observed is due merely to the orthographic and phonological overlap of preview and target. In Experiment 1, we attempted to control for this problem by using an additional group of monolingual subjects for whom the priming effect had to be due only to the orthographic and phonological overlap between preview and target. In Experiment 2, we attempted to control for this problem with previews that we will refer to as pseudocognates (words that are orthographically similar across the two languages but that are not semantically related). As with Pollatsek et al. (1992), in their examination of integrating phonological codes across fixations, we ex- 
amined possible integration of semantic codes across fixations in the present experiments by using converging paradigms: In Experiment 1, we employed a naming task; in Experiment 2, we employed a reading task.

\section{EXPERIMENT 1}

In Experiment 1, we used the single word variant of the boundary paradigm (Rayner, 1978), in which a preview word is initially presented in the parafovea and then replaced by the target word when the subject makes an eye movement toward the preview word. As in most of the prior experiments using the paradigm, we had the subject name the target word. Again, it should be emphasized that the subjects were not aware of the identity of the preview word, nor were they aware of the display change. Occasionally, a display change was noticed (due to less than perfect tracking of the eye on that trial); the subject notified the experimenter and the trial was discarded.

Experiment 1A was run on fluent Spanish-English bilingual subjects (whose characteristics are described below). There were 12 conditions produced by the crossing of three factors. First, the language of the target word could be in either Spanish or English. Second, in either language, there were three preview conditions: identical, translation, and control (in which the control preview was orthographically, phonologically, and semantically different from the target and in the other language). Third, as indicated above, some of the translations were cognates, and others were noncognates. After running Experiment $1 \mathrm{~A}$, we decided that a control for orthographic similarity was needed for the cognate translation condition. Accordingly, in Experiment 1B, we ran English monolingual subjects on the half of the experiment that employed English target words.

\section{Method}

Subjects. Eighteen Spanish-English bilinguals from the University of Massachusetts participated in Experiment $1 \mathrm{~A}$, and $18 \mathrm{En}-$ glish monolinguals from the University of Massachusetts participated in Experiment 1B. They were paid for their participation or received course credit. A summary of the language histories of the bilingual subjects appears in Table 1; all of them were native Spanish speakers. The monolingual subjects had no formal course work or training in the Spanish language.

Stimuli and Design. The stimuli were English and Spanish words, ranging from five to eight letters ( $M=5.6$ letters). The word frequency of the English target words ranged between 0 and 787 $(M=72)$. As indicated above, the design had three crossed factors. First, the target word was in either Spanish or English. Second, for each target word, there were three possible previews: (1) a word identical to the target, (2) a translation of the target, or (3) a control word (an unrelated word in the language opposite to the target). Third, the translation was either a cognate (i.e., orthographically similar to the target) or a noncognate (i.e., having little orthographic resemblance to the target). For the cognate target word cream, the previews were cream, crema, and torre, whereas for the target word crema, the previews were crema, cream, and tower. For the noncognate target word strong, the previews were strong, fuerte, and conejo, whereas for the target word fuerte, the previews were fuerte, strong, and rabbit. All previews had the same number of letters as their target word. There were 54 target words in each language, 18 of which had cognate translations and 36 had noncognate translations. ${ }^{4}$

Because the primary dependent variable was naming latency, and because naming latency is strongly dependent on the initial phoneme of the word to be named, it is necessary to use each target as its own control in a design such as this, in order to have any power. Accordingly, each subject in Experiment 1A saw each of the 108 target words in all three preview conditions, resulting in 324 experimental trials, divided into six blocks. To minimize confusion, the language of the target was held constant within a block, with half the subjects getting the sequence English-Spanish-EnglishSpanish-English-Spanish, and the other half getting the reverse sequence. Within a block, the subjects saw each of the 54 targets in one of the languages exactly once. The preview conditions were counterbalanced across blocks, and the order of trials within a block was randomized independently for each subject. The design was similar in Experiment 1B for the monolingual subjects except that they only had three blocks of trials: the ones with the English targets.

Apparatus and Procedure. The stimuli were presented on a Megatek Whizzard CRT display, which has P-31 phosphor (which decays to $1 \%$ of maximum brightness in $0.25 \mathrm{msec}$ ). Presentation of stimuli was controlled by a VAX 11/730 computer, and, because it was a vector plotting display system, stimulus changes could be accomplished within $2 \mathrm{msec}$. The subjects were seated at a distance of $91 \mathrm{~cm}$ from the monitor, and, at this distance, four characters subtended $1^{\circ}$ of visual angle. All letters were lowercase.

Eye movements were monitored with a Fourward Technologies Dual Purkinje Eyetracker (Generation V), which was interfaced with the computer. The eyetracker has a resolution of less than $10^{\prime}$ of arc, and its signal was sampled every millisecond by the computer. Viewing was binocular, with eye movements recorded from the right eye. Because of the necessity of having a vocal response, a chinrest was employed to keep the head still. Vocal responses were recorded with a microphone and fed into an A to D port of the computer, and a software threshold was set for each subject in the practice session.

At the beginning of the experiment, the eye-tracking system was calibrated for the subject. At the beginning of each trial, a "check calibration" pattern came on with five fixed target crosses and a

Table 1

Characteristics of the Bilingual Subjects in Experiments 1 and 2

\begin{tabular}{|c|c|c|c|c|}
\hline \multirow[b]{2}{*}{ Mean Age } & \multirow{2}{*}{$\begin{array}{l}\text { Mean Number } \\
\text { of Years in U.S. }\end{array}$} & \multirow{2}{*}{$\begin{array}{l}\text { Mean Number } \\
\text { of Years } \\
\text { in U.S. Schools }\end{array}$} & \multicolumn{2}{|c|}{$\begin{array}{c}\text { Average Self-Rating } \\
\text { on Ability to Read/Write* }\end{array}$} \\
\hline & & & English & Spanish \\
\hline \multirow{3}{*}{22} & & Experiment 1 & & \\
\hline & 9 & 8 & 9.3 & 9.4 \\
\hline & & Experiment 2 & & \\
\hline 23.5 & 8 & 7 & 8.4 & 9.2 \\
\hline
\end{tabular}

*On a 10-point scale, in which $10=$ very fluent. 


$\begin{array}{llll}\begin{array}{l}\text { Subject fixates } \\ \text { calibration cross }\end{array} & + & & \\ \text { Fixation } 1 & * & & \\ & & \text { crema } & \text { (preview) } \\ \text { Fixation } 2 & \text { cream } & \text { (target) }\end{array}$

\section{Other possible previews: cream, torre}

Figure 1. Schema of parafoveal preview in naming in Experiment 1. The asterisks indicate the locations of fixations.

\begin{abstract}
calibration cross that moved in synchrony with the eye. If, while the subject was fixating one of the target crosses, there was a discrepancy between the calibration cross and the fixed cross, the subject was recalibrated. When it was determined that the equipment was properly calibrated and that the subject was fixating the central cross, a trial was initiated by the experimenter. During each trial, two words appeared on the screen sequentially. The preview word appeared first, with the leftmost letter $2^{\circ}$ to the right of the central fixation cross. ${ }^{5}$ When the eyes crossed an invisible boundary one half of a degree to the right of the initial fixation point, the preview word was replaced by the target word (see Figure 1). Since the boundary was quite close to fixation and (as indicated above) the apparatus could accomplish a display change within about $2 \mathrm{msec}$, the change was accomplished well before the subject fixated the target word (well within $10 \mathrm{msec}$ after the saccade began). When the subject named the target word, it disappeared from the screen, and the experimenter scored the response for accuracy. The "check calibration" display then appeared, signaling the beginning of the next trial.

Prior to the actual experiment, each subject was given 12 practice trials using different words from those used in the experimental trials. The language of the target words in the practice trials matched the first block of experimental trials for the bilinguals, whereas the monolinguals always named English words. After completing the experiment, the subjects were asked to complete a 3page language-history questionnaire.
\end{abstract}

\section{Results and Discussion}

Bilinguals. The primary data were the naming latencies. These were measured from the time that the subjects' eyes were judged to have crossed the boundary that triggered the display change; therefore, latencies are approximately $10-15 \mathrm{msec}$ longer than if measured from the time that the subjects began fixating the target word. Trials were excluded in which (1) a naming error occurred (misfluent responses were also counted as errors), (2) the response failed to trigger the voice key, (3) the naming latency was either over $1,500 \mathrm{msec}$ or more than $2.5 \mathrm{stan}-$ dard deviations above the mean, or (4) the eye-movement latency was either less than $50 \mathrm{msec}$ or more than $400 \mathrm{msec}$. In all analyses below, the reliability of effects over subjects $\left(F_{1}\right)$ and items $\left(F_{2}\right)$ was assessed. The mean eyemovement latency on nonexcluded trials was $171 \mathrm{msec}$, and there were no effects of preview, cognate condition, or language of the target word on the eye-movement latency (all $F \mathrm{~s}<1)$.

As seen in Table 2, there were clear differences among preview conditions. Preliminarily, the data were analyzed in a $3 \times 2 \times 2$ analysis of variance (ANOVA) with preview condition, target language, and cognate versus noncognate as factors. The three relevant points of this analysis are (1) there was a significant main effect of preview $\left[F_{1}(2,34)=16.3, p<.001 ; F_{2}(2,104)=11.5, p<\right.$ $.001]$, (2) there was a significant preview $\times$ cognate interaction $\left[F_{1}(2,34)=8.04, p<.001 ; F_{2}(2,104)=3.71\right.$, $p<.05$ ], and (3) there was virtually no effect of target language (the main effect and all interactions involving it had $F \mathrm{~S}<1$; see Table 2). As a result, all subsequent analyses ignore target language and focus on the averages across the two languages. The preview $\times$ cognate interaction indicates that the size of the translation benefits differed between the cognates and noncognates, since the identical and control preview conditions were functionally equivalent for cognates and noncognates. In fact, when the data set was examined without the translation condition, the 24-msec advantage of the identical condition over the control condition was significant $\left[F_{1}(1,17)=21.4, p<\right.$ $\left..001 ; F_{2}(1,52)=22.1, p<.001\right]$, and the cognates were 19 msec faster on average than the noncognates $\left[F_{1}(1,17)=\right.$ $12.7, p<.01$; although $\left.F_{2}(1,52)=1.47, p>.20\right]$, but the identical preview effect was virtually the same for the two sets of stimuli $\left(F_{\mathrm{S}}<1\right)$. Since the main effect difference between the cognate and noncognate targets could have merely been due to differences in the initial phonemes in the two stimulus sets, there seems to be no reason to think that there was anything fundamentally different between the two sets except for the experimental manipulation in the translation condition.

Planned contrasts corroborate the above conclusions. First, for the noncognate translations, there was no difference in naming latency $(0 \mathrm{msec})$ between the translation and control conditions. Thus, it appears that a preview that has virtually the same meaning as the target word does not facilitate at all in the absence of ortho- 
Table 2

Naming Latencies (in Milliseconds) and Percent Bad Trials in Experiment 1 as a Function of Language of the Target Word, Preview Condition, and Whether the Translation was a Cognate or a Noncognate

\begin{tabular}{|c|c|c|c|c|c|c|c|c|}
\hline \multirow[b]{4}{*}{ Preview Condition } & \multicolumn{6}{|c|}{ Bilingual Subjects } & & \\
\hline & \multicolumn{4}{|c|}{ Language of Target Word } & \multirow{2}{*}{\multicolumn{2}{|c|}{ Average }} & & \\
\hline & \multicolumn{2}{|c|}{ English } & \multicolumn{2}{|c|}{ Spanish } & & & \multicolumn{2}{|c|}{ Monoligual Subjects } \\
\hline & $\begin{array}{l}\text { Naming } \\
\text { Latency }\end{array}$ & $\begin{array}{c}\% \text { Bad } \\
\text { Trials } \\
\end{array}$ & $\begin{array}{l}\text { Naming } \\
\text { Latency }\end{array}$ & $\begin{array}{c}\% \text { Bad } \\
\text { Trials } \\
\end{array}$ & $\begin{array}{l}\text { Naming } \\
\text { Latency }\end{array}$ & $\begin{array}{c}\% \text { Bad } \\
\text { Trials } \\
\end{array}$ & $\begin{array}{l}\text { Naming } \\
\text { Latency }\end{array}$ & $\begin{array}{l}\% \text { Bad } \\
\text { Trials } \\
\end{array}$ \\
\hline \multicolumn{9}{|c|}{ Cognate } \\
\hline Identical & 643 & 14.5 & 648 & 12.4 & 645 & 13.5 & 557 & 16.7 \\
\hline Translation & 645 & 13.6 & 640 & 13.9 & 643 & 13.8 & 573 & 14.5 \\
\hline Control & 667 & 16.7 & 667 & 10.8 & 667 & 13.8 & 596 & 13.0 \\
\hline \multicolumn{9}{|c|}{ Noncognate } \\
\hline Identical & 630 & 12.5 & 628 & 10.7 & 629 & 11.6 & 546 & 16.2 \\
\hline Translation & 661 & 10.2 & 648 & 13.0 & 655 & 11.6 & 581 & 13.3 \\
\hline Control & 655 & 12.2 & 655 & 12.7 & 655 & 12.5 & 585 & 14.7 \\
\hline
\end{tabular}

graphic and/or phonological similarity. The cognate translations, however, were $24 \mathrm{msec}$ faster than their controls $\left[F_{1}(1,17)=25.6, p<.001 ; F_{2}(1,17)=5.64, p<\right.$ $.03]$ and were actually slightly faster than the identical condition (although $F \mathrm{~S}<1$ ). Moreover, the translation effect for the cognates was significantly bigger than for the noncognates over subjects $\left[F_{1}(1,17)=12.5, p<.01\right]$, but not over items $\left[F_{2}(1,52)=2.38, p=.13\right]$.

There were virtually no naming errors (fewer than $1 \%$ ), but we examined the percentage of bad trials (which included hesitations) to determine whether there were any effects of conditions (see Table 2). As is evident in the table, there was virtually no difference among preview conditions $(F \mathrm{~s}<1)$; however, it is worth commenting that there were at least as many bad trials for the control conditions as for the other two preview conditions, so that the above preview effects in latency were not compromised by a speed-accuracy tradeoff. There did appear to be a few more bad trials for the cognates than for the noncognates $\left[F_{2}(1,52)=5.74, p<.05\right.$; but $F_{1}(1,17)=$ $2.18, p=.16]$, mirroring the slightly longer naming latencies for cognates.

To relieve any concern that the pattern of data (and the preview benefit) appeared only with extensive practice with the same set of items, we did two additional analyses on the subject data. In one, we made trial block an explicit variable, and, although there was a significant block main effect $[F(5,85)=5.36, p<.001]$, all interactions of block with the variables of interest were nonsignificant. In particular, both the interaction of block and preview condition and the interaction of block, preview condition, and cognate versus noncognate had $F$ s less than 1 . In the second analysis, we examined performance only on the first two trial blocks, a span in which no target was repeated in the same language. Here, the pattern was virtually identical to that in the main analysis. The preview effect was significant $[F(1,17)=5.74, p<.01]$, and, although the preview $\times$ cognate interaction was not $[F(2,34)=1.86, p<.20]$, the contrast indicating a different pattern across languages for the translation condition than for the other two conditions was significant $[F(1,17)=$ $6.56, p=.02]$.

There thus appears to be a considerable preview benefit from the cognate translations. There are several possible interpretations of this benefit, however, as indicated earlier. Since these cognate previews generally shared many letters (and many initial letters) with the target words (and had considerable phonological similarity in whatever language they were interpreted in), the benefit could have merely been due to orthographic and/or phonological overlap. In fact, in earlier experiments in English (Rayner et al., 1978; Rayner et al., 1980), orthographically similar previews that shared the first two or three letters with the target provided almost as much preview benefit as identical previews (even for nonword previews). Thus, as indicated earlier, we ran the monolinguals as a control, because these cognate translations would have been orthographically and phonologically similar to the targets for the monolinguals but would not share a common meaning.

Monolinguals. The eye latency for the monolinguals was $176 \mathrm{msec}$ and did not differ significantly across conditions $(F \mathrm{~s}>1)$. The naming latency data for the monolinguals were similar to those for the bilinguals with one apparent exception (see Table 2). As with the bilinguals, the main effect of preview $\left[F_{1}(2,34)=77.6, p<.001\right.$; $\left.F_{2}(2,104)=33.3, p<.001\right]$ and the interaction of preview with cognate versus noncognate $\left[F_{1}(2,34)=5.96\right.$, $\left.p<.01 ; F_{2}(2,104)=4.13, p<.05\right]$ were significant in the overall analysis. When translation previews were eliminated from the analysis, the 39-msec advantage of identical previews over control previews was reliable $\left[F_{1}(1,17)=\right.$ $\left.138.8, p<.001 ; F_{2}(1,52)=54.4, p<.001\right]$. The $11-$ msec advantage of noncognate over cognate targets (only $6 \mathrm{msec}$ in the item analysis) was reliable only over subjects $\left[F_{1}(1,17)=7.34, p<.02 ; F_{2}(1,52)=1.51, p>.20\right]$, and the interaction between the two variables was virtually zero $\left(F_{\mathrm{S}}<1\right.$ in both analyses). The fact that there was a difference between cognates and noncognates in absolute naming time for the monolinguals indicates that there was something different between the two sets of stim- 
uli (most likely the initial consonants) that caused the effect for bilinguals, rather than whether or not they were Spanish-English cognates.

Of greatest interest, however, is the translation effect for the cognates, because the major purpose of running the monolingual group was to assess whether the translation effect observed for the bilinguals was really due to the cognates being translations. Unfortunately, the pattern of data from the monolinguals is a bit difficult to interpret in this regard. There was a significant "translation" effect relative to the controls for the cognates (presumably due merely to orthographic or phonological overlap between preview and target) of $23 \mathrm{msec}\left[F_{1}(1,17)=17.2, p<.001\right.$; $\left.F_{2}(1,17)=14.5, p<.001\right]$, and, unlike for the bilinguals, there was a $16-\mathrm{msec}$ advantage of the identical condition over the cognate translation condition $\left[F_{1}(1,17)=14.5\right.$, $\left.p<.001 ; F_{2}(1,17)=4.54, p<.05\right]$. (The 4-msec translation effect in the subject analysis for the noncognates was nonsignificant, $p \mathrm{~s}>.20$, and was almost certainly due to random variation, since the difference in the item analysis was less than $1 \mathrm{msec}$.)

As can be seen in Table 2, there was little of interest in the percent of bad trials data. (Remember that the actual error rates were far lower.) There was no average difference between the cognates and noncognates $\left(F_{\mathrm{S}}<1\right)$. There was a suggestion that the percentage of bad trials was a bit lower in the translation conditions than in the other two conditions, but only in the subject data $\left[F_{1}(2,34)=2.75, p=.08 ; F_{2}(2,104)<1\right]$. If this effect were real, however, it would be hard to interpret.

We also examined whether the pattern of data changed with increasing practice. As with the bilinguals, naming times got shorter over blocks $[F(2,34)=15.9, p<.001]$, but there was no interaction of practice with any of the preview effects. Somewhat curiously, there was an interaction of practice with cognate versus noncognate $[F(2,34)=$ $5.39, p=.01]$, indicating that times decreased more with practice on the cognates than on the noncognates.

Bilinguals and monolinguals compared. As indicated above, the key reason for comparing the two groups was to elucidate the cognate translation effect for the bilinguals. The problem is that two different comparisons present two different pictures. That is, if one compares the size of the facilitation for the translation condition (relative to the controls), the effects were virtually the same size for the two groups: $24 \mathrm{msec}$ for the bilinguals versus $23 \mathrm{msec}$ for the monolinguals $\left(F_{\mathrm{S}}<1\right)$. These data would seem to argue that the translation effect for the bilinguals was due merely to orthographic or phonological overlap between the cognate previews and the targets. On the other hand, the difference between the cognate translation previews and the identical previews was bigger for the monolinguals $(16 \mathrm{msec})$ than for the bilinguals $(-2 \mathrm{msec})$. However, the difference in this effect between the two groups was significant only in the subject analysis $\left[F_{1}(1,34)<5.47, p=.03 ; F_{2}(1,17)=2.51, p=\right.$ .13]. More generally, the monolinguals were faster than the bilinguals $\left[F_{1}(1,34)=8.82, p<.01 ; F_{2}(1,52)=42.1\right.$, $p<.001]$ and had a bigger difference between identical and control previews (averaged over cognates and noncognates) $\left[F_{1}(1,34)=6.16, p<.05 ; F_{2}(1,52)=4.46, p<.05\right] .^{6}$

To summarize, one could view the data as showing that there was a true translation effect for the bilinguals, since they showed as big a preview effect for cognate translation previews as they did for identical previews, whereas the monolinguals showed only about half as big a cognate translation preview effect as an identical preview effect. This would suggest that, for the monolinguals, the orthographic and/or phonological similarity of the previews did not produce a full identical preview effect. However, the absolute size of the cognate translation preview effect was the same for the two groups, which seems to argue against the hypothesis that some part of the cognate translation preview effect for the bilinguals was due to the stimuli being translations. We will return to this issue in the General Discussion section.

\section{EXPERIMENT 2}

The key issue of this study was whether or not subjects extract semantic information from parafoveal previews that allows them to identify the word better when they fixate it later. In Experiment 1, using a naming paradigm, we came up with one clear answer and one ambiguous answer to this. The data clearly established that there was no such benefit when the translation was orthographically different from the target. When the translation was a cognate, however, the data were more ambiguous: One could make a case that there was preview benefit from cognate translations when looking at one aspect of the data, but one could make the opposite case when looking at another aspect of the data. The comparison across the bilingual and monolingual groups, however, is clouded by absolute differences in naming time and, related to that, perhaps differences due to the fact that the bilinguals have many more words in their lexicon.

Experiment 2 was designed to explore these issues using a boundary technique in which subjects silently read sentences, and one word was designated as a target word. A preview word was present in the target word location before the subject's eye crossed an invisible boundary (to the left of the space preceding the target word). When the boundary was crossed, the preview word turned into the target word (see Figure 2). As in Experiment 1, the subjects were unaware of the identity of the preview word and the display change.

The design was similar to that of Experiment 1 in that three preview conditions were employed, and the targets (together with the sentence frame) were in either Spanish or English. (The target word was always in the same language as the sentence frame.) However, there were now three target conditions. Two were the same as in Experiment 1: targets with either cognate or noncognate translations. In fact, all 54 targets employed in Experiment 1 were also employed in Experiment 2 . The chief difference was that a group of 18 pseudocognate targets was added, which had "pseudotranslations" that were words in the other language that were about as orthographically sim- 


\author{
$*$ \\ The chocolate cake was very dulce and much too high in calories. (Fixation n-1) \\ The chocolate cake was very sweet and much too high in calories. (Fixation $\mathrm{n}$ )
}

\title{
Other possible previews: sweet, grito
}

Figure 2. Schema of parafoveal preview in reading in Experiment 2. The asterisks indicate the locations of fixations, and the vertical lines indicate the locations of the boundary.

ilar to their targets as were the cognate translations but that were not at all semantically related to the targets. The addition of these stimuli was felt to be, in many ways, a better control for the cognate translation condition, and, thus, no monolingual group was run on the English sentences. Two of the preview conditions, the identical condition and the control condition, were identical to those in Experiment 1. The third, which we will refer to as the similar condition, is somewhat different from that in Experiment 1 , since it contained (1) translations in the two translation conditions and (2) pseudotranslation controls in the pseudocognate condition.

\section{Method}

Subjects. Fifty-four Spanish-English bilinguals, none of whom had participated in Experiment 1, participated in Experiment 2. They were paid for their participation or received course credit. A summary of the language histories for the subjects appears in Table 1; all were native Spanish speakers.

Stimuli and Design. All of the target words were embedded in neutral sentential contexts, and the subjects were asked to read the sentences (half were in Spanish, and half were in English). As in Experiment 1, the design had three crossed factors. First, the target word was in either Spanish or English. Second, for each target word, there were three preview words: (1) a word identical to the target, (2) a word semantically and/or orthographically similar to the target, or (3) an unrelated control word in the opposite language. Third, there were three sets of targets, for which the relation of the similar preview to the target was different: In the noncognate set, the similar word was a noncognate translation; in the cognate set, the similar word was a cognate translation; and in the pseudocognate set, the similar word in the opposite language was as orthographically similar to the target word as the cognate translation but was not at all semantically related to the target. The subjects read 144 experimental sentences ( 72 targets in each language-18 cognates, 18 pseudocognates, and 36 noncognates), so that they saw each target word and its sentence frame once. Table 3 gives an example English sentence for each of the three types of target words, along with the possible preview words for each target word. Half of the subjects read the English sentences first, and the other half read the
Spanish sentences first. Because each sentence frame was used only once, the preview conditions were counterbalanced across subjects. The sentences in each half of the experiment were presented in a different random order to each subject.

Apparatus and Procedure. The target sentences were presented in lowercase letters (except when uppercase letters were appropriate) on a ViewSonic $17 \mathrm{G}$ monitor (with standard VGA characters), which was controlled by a super-VGA graphics board with a Tseng chip interfaced with a 486 computer. All sentences were presented on a single line, with a maximum length of 72 characters. The subjects were seated $61 \mathrm{~cm}$ from the monitor, and four characters equaled $1^{\circ}$ of visual angle. The brightness of the monitor was adjusted to a comfortable level for each subject and was held constant throughout the experiment. The letters were presented in light cyan (on a black background) by mixing the green and blue input signals on the display monitor with a P-22 phosphor, which allowed blanking of the display to produce a drop to $10 \%$ of maximum brightness in $0.06 \mathrm{msec}$. The eye-tracking system that was used in Experiment 1 was interfaced with the monitor and computer in Experiment 2. Because the task was silent reading, the chinrest in Experiment 1 was replaced with a bite bar, which served to eliminate head movements.

At the beginning of the experiment, the eye-tracking system was calibrated for each subject. Prior to each trial, the "check calibration" pattern appeared on the monitor. If the calibration was good, the subject was instructed to fixate on the leftmost calibration cross, and the experimenter initiated a trial. This resulted in the appearance of a sentence with a preview word in the target word location. When the subject's eye crossed an invisible boundary (set at the last character of the word preceding the target word), the preview word was replaced by the target word. The display change was accomplished in $6.25 \mathrm{msec}$, so that changes typically occurred during the saccade that crossed the boundary location. When the subject finished reading the sentence, he or she pressed a button that blanked the monitor. Then, either a yes/no comprehension question was given or the calibration pattern reappeared on the monitor. Questions were asked on one fourth of the trials: The subjects responded to the question by a pressing a left ("yes") or right ("no") button on a response box. The subjects had little difficulty answering the questions. Prior to reading the 72 experimental sentences in each language, the subjects received 20 practice sentences. As in Experiment 1, any trial on which a display change was noticed was eliminated.

Table 3

Example English Sentences in Experiment 2 With the

Target Word (Underlined) and the Translation and Control Previews

\begin{tabular}{ll}
\hline Target Type & \multicolumn{1}{c}{ Sentence } \\
\hline Translation & That new brand of paper towel is strong (fuerte/hambre) and has a lower price. \\
Cognate & The kitten was given a bowl of cream (crema, torre) along with two soft toys. \\
Pseudocognate & Steve's mom asked him to cut the grass (grasa, falda) before he went out. \\
\hline
\end{tabular}


Table 4

Fixation $n-1$ Durations (in Milliseconds) and Percent of Time the Target Word Region Was Skipped (\% Time Skipped) as a Function of Target Type, Preview, and Language of Target

\begin{tabular}{|c|c|c|c|c|c|c|}
\hline \multirow[b]{3}{*}{ Target Type } & \multicolumn{6}{|c|}{ Preview } \\
\hline & \multicolumn{2}{|c|}{ Identical } & \multicolumn{2}{|c|}{ Similar } & \multicolumn{2}{|c|}{ Control } \\
\hline & $\begin{array}{c}\text { Fixation } n-1 \\
\text { Duration }\end{array}$ & $\begin{array}{l}\% \text { Time } \\
\text { Skipped }\end{array}$ & $\begin{array}{c}\text { Fixation } n-1 \\
\text { Duration }\end{array}$ & $\begin{array}{l}\% \text { Time } \\
\text { Skipped }\end{array}$ & $\begin{array}{c}\text { Fixation } n-1 \\
\text { Duration }\end{array}$ & $\begin{array}{l}\text { \% Time } \\
\text { Skipped }\end{array}$ \\
\hline \multicolumn{7}{|c|}{ English Target } \\
\hline Cognate & 262 & 8.3 & 265 & 6.5 & 262 & 5.8 \\
\hline Pseudocognate & 256 & 8.0 & 263 & 3.5 & 262 & 3.4 \\
\hline Noncognate & 260 & 7.4 & 265 & 5.4 & 264 & 4.8 \\
\hline Average & 260 & 7.9 & 264 & 5.1 & 263 & 4.7 \\
\hline \multicolumn{7}{|c|}{ Spanish Target } \\
\hline Cognate & 268 & 4.9 & 266 & 3.3 & 274 & 3.4 \\
\hline Pseudocognate & 266 & 5.1 & 277 & 3.9 & 277 & 1.9 \\
\hline Noncognate & 270 & 6.3 & 272 & 4.1 & 269 & 5.2 \\
\hline Average & 268 & 5.4 & 272 & 3.8 & 273 & 3.5 \\
\hline \multicolumn{7}{|c|}{ Combined } \\
\hline Cognate & 265 & 6.6 & 266 & 4.9 & 268 & 4.6 \\
\hline Pseudocognate & 261 & 6.6 & 270 & 3.7 & 270 & 2.7 \\
\hline Noncognate & 264 & 6.9 & 269 & 4.8 & 267 & 5.0 \\
\hline Average & 264 & 6.7 & 268 & 4.5 & 268 & 4.1 \\
\hline
\end{tabular}

\section{Results and Discussion}

Across all trials in the experiment, $5 \%$ of the data were lost due to track losses of the eye-tracking system. Trials on which the display change occurred at the very end of a saccade $(3 \%)$ were also eliminated from further analyses. Consistent with typical reading experiments using eye movements, we examined a number of different variables. However, we will focus on two measures reflecting processing prior to fixating on the target word: (1) the duration of the fixation $(n-1)$ prior to fixating the target word and (2) the skipping rates (i.e., whether or not the subject fixated on or skipped over the target word on his/her initial encounter with it). We will also focus on two "first-pass" fixation time measures: (1) first-fixation duration and (2) gaze duration on the target word (both are defined below).

Fixation $n-1$ and skipping rates. Of primary interest among all the eye-movement measures that are possible are those assessing processing either immediately before the boundary was crossed or immediately after the boundary was crossed, since these are most relevant to the influence of the preview on identifying the target word. The earliest measures of interest are the duration of fixation $n-1$ and the probability of skipping the target word region.

With respect to the duration of fixation $n-1$, if subjects notice anything peculiar about the target location prior to reaching that word (such as the fact that a word from the opposite language was present in the target location), presumably that fixation would be inflated. As can be seen in Table 4, there was no evidence of such an effect. There was a main effect of language, in that fixations were longer when the sentence was in Spanish $(271 \mathrm{msec})$ than when it was in English $(262 \mathrm{msec})$
$\left[F_{1}(1,53)=7.26, p<.01 ; F_{2}(1,69)=6.87, p<.05\right]$, but there were no other significant main effects or interactions (all $p s>.20$ ). Thus, there is no evidence that the subjects detected anything unusual about the target location prior to fixating that region.

With respect to skipping, if the translation preview was skipped more often than the control preview for the noncognate targets, it would be evidence that the meaning of the preview had been identified on at least some trials. Similarly, it would also be evidence for semantic processing if the skipping rate was greater in the similar condition for the real cognates than for the pseudocognates. In contrast, if there were equal skipping rates for cognates and pseudocognates in the similar condition that were greater than those for the controls, it would most plausibly be due to these words being misidentified as the targets because of orthographic and/or phonological overlap between preview and target. As can be seen in Table 4, there were some differences among the skipping rates (though relatively small). First, there was more skipping of English targets than Spanish targets (perhaps reflecting somewhat greater fluency in reading English) $\left[F_{1}(1,53)=\right.$ $\left.5.86, p<.05 ; F_{2}(1,69)=5.22, p<.05\right]$. More important, there was a significant main effect of preview $\left[F_{1}(2,106)=\right.$ $\left.7.82, p<.001 ; F_{2}(2,138)=5.74, p<.01\right]$, indicating that some aspect of the preview stimuli had been processed. However, as can be seen in Table 4, virtually the whole effect was due to the identical previews being skipped $2.2 \%$ more than the similar previews $\left[F_{1}(1,53)=\right.$ $\left.12.1, p<.001 ; F_{2}(1,69)=7.19, p<.01\right]$ and $2.6 \%$ more than the control previews $\left[F_{1}(1,53)=9.20, p<.01\right.$; $\left.F_{2}(1,69)=8.03, p<.01\right]$. In contrast, the $0.4 \%$ difference between the similar and control conditions was not close to reliable $\left(F_{\mathrm{S}}<1\right)$, nor was there any interaction 
Table 5

Experiment 2: Gaze and First-Fixation Durations (in Milliseconds) as a Function of Target Type, Preview, and Language of Target

\begin{tabular}{|c|c|c|c|c|c|c|}
\hline \multirow[b]{3}{*}{ Target Type } & \multicolumn{6}{|c|}{ Preview } \\
\hline & \multicolumn{2}{|c|}{ Identical } & \multicolumn{2}{|c|}{ Similar } & \multicolumn{2}{|c|}{ Control } \\
\hline & $\begin{array}{c}\text { Gaze } \\
\text { Duration }\end{array}$ & $\begin{array}{c}\text { First-Fixation } \\
\text { Duration } \\
\end{array}$ & $\begin{array}{c}\text { Gaze } \\
\text { Duration }\end{array}$ & $\begin{array}{c}\text { First-Fixation } \\
\text { Duration } \\
\end{array}$ & $\begin{array}{c}\text { Gaze } \\
\text { Duration }\end{array}$ & $\begin{array}{c}\text { First-Fixation } \\
\text { Duration } \\
\end{array}$ \\
\hline \multicolumn{7}{|c|}{ English Target } \\
\hline Cognate & 327 & 265 & 333 & 270 & 365 & 286 \\
\hline Pseudocognate & 327 & 261 & 336 & 265 & 360 & 285 \\
\hline Noncognate & 320 & 263 & 357 & 283 & 368 & 287 \\
\hline \multicolumn{7}{|c|}{ Spanish Target } \\
\hline Cognate & 357 & 269 & 355 & 270 & 377 & 300 \\
\hline Pseudocognate & 347 & 272 & 363 & 282 & 385 & 295 \\
\hline Noncognate & 354 & 277 & 377 & 290 & 377 & 291 \\
\hline \multicolumn{7}{|c|}{ Combined } \\
\hline Cognate & 342 & 267 & 344 & 270 & 371 & 292 \\
\hline Pseudocognate & 337 & 266 & 350 & 273 & 373 & 290 \\
\hline Noncognate & 337 & 270 & 367 & 287 & 373 & 289 \\
\hline
\end{tabular}

of this latter difference with target type $(F \mathrm{~s}<1)$. It thus appears that when the actual target word is seen in the parafovea, it is skipped a bit more than when a "wrong" word is in that location. This effect (and the skipping rate in general) is small, probably because the target words were not predictable. An examination of Table 4 indicates that there was a small increased skipping rate for orthographically similar previews (actually a somewhat bigger effect for the pseudotranslations than for the real translations); however, the difference between these orthographically related previews and the control previews (i.e., when the noncognate translations were removed from the analysis of similar vs. control) was far from significant $\left(F_{\mathrm{S}}<1\right)$. There is thus no evidence that the meaning of the translation was employed in the decision to skip, and there is only a hint that orthographically similar previews were skipped more than control previews.

First-pass fixation measures on the target word. The two most common measures of lexical processing of words in reading are (1) first-fixation duration, which is the average duration of the first fixation (or only fixation) on the target word (assuming it was preceded by a forward saccade), and (2) gaze duration, which is the average of the summed fixation durations on a word before a saccade leaves the word (again assuming the first fixation on the word was preceded by a forward saccade). In both cases, the means are computed only from trials on which the word was not skipped originally - that is, the averages are conditional on the words being fixated on the "first pass" through the text. As can be seen in Table 5, not only the pattern of data but the sizes of the effects for both duration measures were remarkably similar to those from the naming latencies in Experiment 1.

First, consider the first-fixation durations, which reflect early processing of the target word. As with the skipping rates, there was a main effect of language, with fixation times being somewhat longer in $\operatorname{Spanish}\left[F_{1}(1,53)=\right.$ $\left.7.35, p<.01 ; F_{2}(1,69)=8.66, p<.01\right]$. More important, there was a clear effect of preview $\left[F_{1}(2,106)=38.1, p<\right.$ $\left..001 ; F_{2}(2,138)=16.87, p<.001\right]$ and a clear interaction between preview type and target type $\left[F_{1}(4,212)=\right.$ $\left.4.20, p<.01 ; F_{2}(4,138)=3.98, p<.05\right]$. Subanalyses indicated that this interaction of target type with preview type was significant when comparing cognate targets with noncognate targets $\left[F_{1}(2,106)=6.90, p<.01 ; F_{2}(2,138)=\right.$ $5.88, p<.01]$ and when comparing pseudocognate targets with noncognate targets $\left[F_{1}(2,106)=4.24, p<.05\right.$; $\left.F_{2}(2,138)=3.86, p<.05\right]$; however, the difference between real cognate targets and pseudocognate targets was not close to significant $\left(F_{\mathrm{S}}<1\right)$. The above analyses indicate that there were significantly bigger translation effects for the cognates and pseudocognates than for the noncognates, but because the cognates and pseudocognates did not differ, these differences were due merely to orthographic and/or phonological overlap between preview and target. ${ }^{7}$

We also conducted two somewhat more powerful analyses. The first analysis involved only the similar and control conditions (i.e., looking at translation effects). When cognate and pseudocognate targets were compared, the average similarity effect (the difference between the similar and control conditions) of $20 \mathrm{msec}$ was highly reliable $\left[F_{1}(1,53)=24.8, p<.001 ; F_{2}(1,69)=7.92, p<\right.$ $.01]$, but the difference between the 22 -msec translation effect for cognates and the 17-msec pseudotranslation effect for pseudocognates was not close to significant $\left[F_{1}(1,53)=1.76, p=.19 ; F_{2}<1\right]$. In addition, the 2 msec translation effect for noncognates was not close to significant $\left(F_{\mathrm{S}}<1\right)$. The second analysis was an analogous comparison of the similar and identical conditions. When the cognate and pseudocognate targets were compared, the 5-msec average difference between identical and orthographically similar conditions, somewhat surprisingly, was reliable over subjects $\left[F_{1}(1,53)=9.48, p<\right.$ 
$\left..01 ; F_{2}(1,34)=2.66, p>.10\right]$, but the difference between the 7-msec difference for the pseudocognate targets and the 3-msec difference for the cognate targets was not $\left(F_{\mathrm{S}}<1\right)$. It is also worth noting that the $17-\mathrm{msec}$ difference between the identical and similar conditions for the noncognate translations was highly reliable $\left[F_{1}(1,53)=\right.$ $\left.22.4, p<.001 ; F_{2}(1,69)=18.8, p<.001\right]$.

To summarize, the first-fixation data showed clear preview effects. Identical previews provided a clear preview benefit (relative to the controls), and cognate and pseudocognate translations provided almost as much benefit. However, virtually all of the benefit appeared to be due to orthographic and/or phonological similarity of the preview to the target: (1) There was virtually no preview benefit for noncognate translations, and (2) there were only small unreliable differences between cognate translations and pseudocognate pseudotranslations, using either the control condition or the identical condition as a baseline.

As can be seen in Table 5, the pattern of data for the gaze durations was similar to that of the first-fixation duration. As with the first fixations, the subjects had somewhat longer gazes when reading Spanish $\left[F_{1}(1,53)=\right.$ $\left.5.24, p<.05 ; F_{2}(1,69)=15.0, p<.001\right]$, and there were reliable preview effects $\left[F_{1}(2,106)=24.8 ; p<.001\right.$; $\left.F_{2}(2,138)=15.2, p<.001\right]$, but the preview $\times$ target type interaction was not significant $\left[F_{1}(4,212)=2.24\right.$, $\left.p=.07 ; F_{2}(4,138)=1.43, p>.20\right]$.

Since the omnibus interaction is not the most powerful examination of the translation effects, we did further planned contrasts on translation effects similar to those on the first-fixation data. The first analysis examined differences between the similar and control conditions. When the cognate and pseudocognate targets were compared, the average 25 -msec difference between the similar and control conditions was significant $\left[F_{1}(1,53)=\right.$ $\left.12.8, p<.001 ; F_{2}(1,34)=5.63, p<.05\right]$, but the difference between the 27 -msec translation effect for the cognates and the 23-msec pseudotranslation effect for the pseudocognates was not $\left(F_{\mathrm{s}}<1\right)$. The 6-msec translation effect for the noncognates was also not significant $\left[F_{1}(1,53)=1.32, p>.20 ; F_{2}<1\right]$. The second analysis examined differences between the identical and similar conditions. When the the identical and similar conditions were compared for the cognate and pseudocognate targets, neither the 8 -msec average difference $\left[F_{1}(1,53)=\right.$ $\left.2.35, p=.13 ; F_{2}(1,34)<1\right]$ nor the contrast between the 2 -msec value for the cognates and the 13 -msec value for the pseudocognates $\left[F_{1}(1,53)=1.07, p>.20 ; F_{2}(1,34)<\right.$ 1] was close to significant. In contrast, the 30 -msec difference between identical and translation conditionsfor the noncognate translations was highly reliable $\left[F_{1}(1,53)=\right.$ $\left.15.4, p<.001 ; F_{2}(1,34)=21.4, p<.001\right]$.

To summarize, the first-fixation and gaze duration data had the same pattern, which replicated the naming data of Experiment 1. First, there was virtually no translation effect in either measure for the noncognates. Second, there was a translation effect for the cognates, but it was not significantly bigger than the pseudotranslation effect for the pseudocognates, so that the simplest inter- pretation of this translation effect is that it was due merely to orthographic and/or phonological overlap between preview and target. There was, however, a hint of a difference in preview benefit between the cognates and the pseudocognates.

We should quickly point out that the nonsignificance of this difference was not due to a "power problem" as standardly understood: This was perhaps the largest boundary study ever done. Assuming that the effect size of the differences between cognates and pseudocognates was the observed mean difference, we estimated that it would take hundreds of subjects to achieve standard statistical significance. To illustrate, the 11-msec interaction reported near the end of the last paragraph was the largest effect reported suggestive of semantic information being integrated across fixations (the $F_{1}$ value was 1.07). Assuming that $11 \mathrm{msec}$ was the true size of the effect and assuming that the observed standard error of $11 \mathrm{msec}$ was the true standard error for 54 participants, it would have taken 212 participants to get a significant effect over participants $\left(\alpha=.05\right.$, two-tailed). In addition, the $F_{2}$ for this comparison was less than 1 , and having more participants would not guarantee that the item variability would decrease appreciably and, thus, that one would have anything close to significance over items even with 212 participants. Moreover, we doubt the power could be increased by using more items, since our translation set was virtually the entire set of noun pairs that were reasonably common in both languages that had the same number of letters. ${ }^{8}$

As a result of the impracticability of running hundreds of subjects, we examined the present data more carefully to see whether these differences between cognates and pseudocognates had any substance. For gaze durations, we constructed three contrasts examining the difference between the translation effect for the cognate targets and the pseudotranslation effect for the pseudocognate targets on three measures: (1) the similar condition minus the average of the identical and control baselines, (2) similar minus identical, and (3) similar minus control. (The first contrast may be the most powerful because it effectively combines both baseline conditions.) Consistent with Table 5 (except for rounding error using the table values), the means over subjects for these three measures were 8,11 , and $4 \mathrm{msec}$, respectively; however, the medians over subjects for the same three contrasts were $1,-8$, and $1 \mathrm{msec}$, respectively. ${ }^{9}$ That is, when one examines the median values over subjects, it appears that there is either virtually no difference between the cognate translation and pseudocognate conditions or that the median goes in the opposite direction from the mean. Thus, we think that it is relatively safe to assume that the null hypothesis is true and that there is no true difference in the pattern between the cognate translation and pseudocognate conditions.

Other eye-movement measures. We also examined three other measures to make certain that there was nothing unusual in the data patterns. First, analysis of the spillover fixation (the duration of the fixation after leav- 
ing the target word) also yielded longer fixations for Spanish $(283 \mathrm{msec})$ than for English $(274 \mathrm{msec})(p<$ .05 ), but no other effects were significant (all $p \mathrm{~s}>.20$ ). Second, the total time data (which includes the gaze duration plus the duration of any regressions made to the target word) yielded the same pattern of effects (though generally even larger differences) as the gaze duration measure. Finally, we did a distance analysis in which we determined the location of the fixation prior to the display change and then computed first-fixation duration and gaze duration as a function of whether the subject was close to (less than six letters from the beginning of the target word) or far from (six or more letters away from the beginning of the target word) the target word on the prior fixation. This analysis revealed the same patterns that are presented in Table 5 for both conditions; however, preview benefit was somewhat stronger in the close condition and somewhat attenuated in the far condition.

\section{GENERAL DISCUSSION}

In two experiments, we examined semantic parafoveal preview effects in word identification using different techniques: In Experiment 1, we examined naming latencies of words in isolation; In Experiment 2, we primarily examined first-fixation durations and gaze durations on the same words when they were read silently in sentential context. In both experiments, the focus was on whether processing of a target word is facilitated by a prior preview of its translation seen in the parafovea. For the noncognate translations, the answer was quite clear in both experiments: There was no facilitation. In Experiment 1 , the mean difference in naming time between the noncognate translations and controls was $0 \mathrm{msec}$; in Experiment 2, the mean difference between the noncognate translations and controls was $2 \mathrm{msec}$ in first-fixation duration and $6 \mathrm{msec}$ in gaze duration. Even the last suggestion of an effect is probably illusory, since the median difference in gaze duration over subjects was less than $1 \mathrm{msec}$.

It thus seems quite clear from these data that either (1) semantic codes of the noncognate translations were not extracted from the parafovea or (2) semantic codes were extracted but, because of large differences in the orthographic or phonological codes between the preview and target, these codes were discarded. One simple example of the latter hypothesis is that if the orthographic difference between the preview and target exceeds some threshold, a signal goes out to the word identification system to erase the information from the prior stimulation. The latter option, however, seems implausible because subjects are not aware of these display changes. It also seems implausible given that Pollatsek et al. (1992) found significant phonological preview effects even when there was significant orthographic mismatch between preview and target, and Pollatsek, Tan, and Rayner (2000) found phonological benefit for Chinese characters in a naming task even when there was no orthographic similarity between parafoveal preview and target. Thus, one would have to posit that, for some reason, the system discards semantic information when the preview is orthographically dissimilar from the target but does not discard phonological information.

The data from the cognate translations, however, are slightly more ambiguous. In Experiment 2, there was a slightly larger mean preview benefit from the cognate translations than from the pseudocognates for both firstfixation duration and gaze duration. These mean differences, however, were far from reliable. Moreover, the median values on three different contrasts that would most directly assess whether there was a bigger benefit from a cognate preview and a pseudocognate preview either were virtually equal to zero $(1 \mathrm{msec})$ or were in the opposite direction from the mean $(-8 \mathrm{msec})$. Therefore, we think the reading data of Experiment 2 are a fairly clear negative result: In silent reading, there was virtually no benefit from having a cognate translation other than what can be ascribed to its orthographic or phonological similarity to the target. The cognate translation data of Experiment 1 , however, were a bit more ambiguous. On the one hand, the preview benefit for the cognates for the bilinguals was virtually the same as that for the monolinguals (indicating no benefit due to these stimuli being translations). However, there was a substantial difference between identical and cognate translation previews for the monolinguals, whereas there was no difference for the bilinguals. This suggests that the cognate translation had a different status for the two groups and, thus, that something about its meaning may have been processed by the bilingual subjects.

To summarize, the data of Experiment 2 indicate that there is no translation effect for either cognates or noncognates, and the data of Experiment 1 indicate that there is no translation effect for the noncognates; however, there is one part of the data of Experiment 1 that might be interpreted as indicating a translation effect for the cognates. We think that the most parsimonious hypothesis to explain the pattern of data is that there was no semantic preview effect in either experiment and that there is some other explanation for the difference in pattern on the cognate translation targets for the bilingual and monolingual subjects in Experiment 1. In particular, it seems quite implausible that a semantic preview effect would show up in a naming task (in which the task is to produce a vocal response) but not in a reading task (in which the task is to extract meaning from the text). Moreover, the data pattern does not indicate that the bilinguals got a bigger preview benefit from the cognate translation than did the monolinguals; rather, it indicates that the bilinguals merely got a smaller benefit from an identical preview.

We think there are two likely causes of the smaller identical preview effects for the bilinguals than for the monolinguals (which are not necessarily mutually exclusive). The first is that the bilinguals have an orthographic and/or phonological "lexicon" with more entries in it than the monolinguals. That is, if one assumes something like an interaction-activationmodel (McClelland \& Rumelhart, 1981), if a lexicon is more densely packed with more 
orthographic and/or phonological "neighbors" or "nearneighbors," one might expect a diffusion of excitation produced by parafoveal visual input across a wider number of entries when a word is presented. As a result, one might expect less of a difference between the activation of the lexical entry of a word when the actual word is presented and the activation of the same lexical entry when produced by something similar. The second is that the bilinguals are somewhat less fluent in both English and Spanish than the monolinguals are in English. A plausible consequence of their lesser fluency in reading is that there would be less excitation of the lexical entry for the stimulus actually presented in the parafovea, relative to the background noise.

Unfortunately, we do not have any direct evidence to support either hypothesis. To date, we have not looked at whether the size of preview benefit is dependent on reading ability, ${ }^{10}$ and we do not have any data on whether neighborhood density affects preview benefit (although it is clear that having more high-frequency neighbors does interfere with reading; see Perea \& Pollatsek, 1998, and Pollatsek, Perea, \& Binder, 1999). Nonetheless, it seems reasonably plausible that either or both of these hypotheses can explain why the bilinguals got less preview benefit from identical previews than did the monolinguals.

We also need to consider an uninteresting reason for a null translation preview effect. Since the language of presentation was blocked in both experiments, one might argue that the bilinguals activated a "switch" that blocked out activation of the lexical entries other than in the language that they were attempting to decode. If so, then our results do not necessarily mean that semantic codes are not generally activated in the parafovea. Rather, our results suggest that the lexical entries in the "wrong" language may be shut down in some circumstances. (We should note that we considered randomizing the language of the target from trial to trial, but we rejected that option because it clearly would have resulted in much more variable data with high error rates. ${ }^{11}$ ) However, we think such an all-or-none switching or filtering notion is fairly unlikely, given that there are a number of studies indicating that word identification is quite automatic, as evidenced by interlingual Stroop effects (Altarriba \& Mathis, 1997; Gerhand et al., 1995; Tzelgov et al., 1990).

We note here two other relevant points. First, unlike the study by Rayner et al. (1986) in which the preview words and target words were also presented in a standard priming situation (i.e., the preview or prime word was presented for $250 \mathrm{msec}$ followed by the target word, which the subject named), we did not use our stimuli in a standard supraliminal priming situation. However, studies using standard supraliminal priming paradigms (Cristoffanini, Kirsner, \& Milech, 1986; de Groot \& Nas, 1991) have typically obtained facilitatory effects for both cognates and translation primes. Such results also imply that fluent bilinguals have a shared lexicon for their two languages. Second, when short prime durations are used and the prime is masked, there is typically priming from cognate translations but not from noncognate transla- tions (de Groot \& Nas, 1991). This suggests that when the prime is perceptually degraded, priming for cognates is due to orthographic/phonological similarity (Bowers, 1999). This latter pattern of results is consistent with the results reported here.

\section{Why Isn't There Semantic \\ Preprocessing in Reading?}

Above, we have entertained alternative views of our data to the one that we think is the most parsimonious: that semantic codes of written words either are not extracted from unidentified parafoveal words or, if they are, are not used when the word is later fixated. In addition to being the most parsimonious explanation of the present data, it is also the explanation most consistent with the prior data reviewed in the introduction. That is, not only do translations produce no preview benefit but semantic associates within the same language that produce priming in a standard foveal priming paradigm (with naming latency as the dependent variable) also produce no preview benefit in reading (Rayner et al., 1986). Likewise, as mentioned earlier, the preview benefit is the same for initial morphemes (e.g., cowxxx as a preview for cowboy) as for pseudomorphemes (e.g., carxxx for carpet), although they both produce benefit, relative to an uninformative preview (Inhoff, 1989). The latter result is somewhat analogous to our cognate versus pseudocognate comparison.

It thus appears that there is considerable evidence that is consistent with the notion that semantic codes are not ex tracted from unidentified parafoveal words (or at least are of no value when the word is later fixated). Although this result seems clear, it appears to contradict the wellestablished finding that people skip words in reading, most notably when they are predictable from the prior text (e.g., Balota et al., 1985). Note that this skipping effect is not merely guessing: Readers skip more often when the predictable word is present in the text than when some other word or nonword of equal length is in the same location. This finding indicates that, in some sense, the meaning of the parafoveal word is extracted on those occasions. However, that might be quite different from extracting semantic features of a parafoveal word. That is, on some occasions (most clearly when a word is highly predictable), the subject may form an expectation that a particular word will appear next. If the word in the parafovea matches this expectation, then the word can be skipped. Note, however, that this does not necessarily imply that the semantics of the parafoveal word are extracted from the orthographic form. Instead, all that may be needed to produce skipping is information that a sufficient match with the lexical form of the expected word has been achieved. In fact, we think it most plausible, consistent with the EZ-Reader model of reading (Reichle, Pollatsek, Fisher, \& Rayner, 1998), that the decision to move the eye (including skipping decisions) is usually based on a fairly superficial process of orthographic analysis that we termed a familiarity check and not on extraction of semantic codes from the word. 
A similar argument can explain why one gets a parafoveal Stroop effect (e.g., Brown, Roos-Gilbert, \& Carr, $1995)$ in which a word presented parafoveally can interfere with naming a foveally presented color patch. This suggests that the meaning of the parafoveal word has been extracted. However, the effect can be explained by interference at a phonological level: Orthographic information from the word excites the phonological representation of the parafoveally presented word sufficiently to cause competition between the name of the word and the name of the color patch.

The finding that brief, and often subliminal, foveal presentations of stimuli can produce semantic priming (sometimes producing as large a priming effect as when the prime is fully visible) is in apparent contradiction to the present and past findings that semantic information is not extracted from the parafovea. Why this should be so is frankly a mystery. That is, why should a 200- to 250-msec parafoveal view of a word produce no evidence for the activation of semantic codes, whereas a much briefer, and even subliminal, foveal view of a word produces semantic priming (Balota, 1983; Carr, McCauley, Sperber, \& Parmelee, 1982; Marcel, 1983) and, thus, quite clear evidence for semantic activation? It is not the difference between reading in context versus single-word identification, since studies in our laboratory using the "fastpriming" technique (Lee, Rayner, \& Pollatsek, 1999; Sereno, 1995; Sereno \& Rayner, 1992) have demonstrated semantic priming effects for briefly exposed foveal words during an eye fixation in reading. The fast-priming technique is quite similar to the boundary paradigm used in Experiment 2, except that the preview for the target word is initially a random string of letters (to preclude any type of preview benefit). When the subject's saccade crosses the boundary location, the random string of letters is replaced by a prime word for $25-50 \mathrm{msec}$, which in turn is replaced by the target word. When the prime is presented for roughly $30-35 \mathrm{msec}$, it is not consciously registered by the reader, but it does result in shorter gaze durations on the target word if it is semantically related to the target.

So why doesn't a similar manipulation with the prime presented as the preview (as in Experiment 2, and in Rayner et al., 1986) yield shorter fixations on the target word? One possibility is that a brief foveal prime and a longer presented parafoveal prime are degraded in different ways. The foveal prime is degraded via temporal duration; however, in the 30-35 msec during which the prime is in the center of vision, most of the details about the letters are available and, hence, registered in the processing system. The parafoveal primes, in contrast, may be sufficiently degraded by acuity limitations, such that the processing system makes no decisive commitment to any semantic (as opposed to lexical) coding.

\section{Summary}

The results of the present study are consistent with the results of other research (Balota et al., 1985; Rayner et al., 1986; Rayner et al. 1980) in indicating that seman- tic codes from an unidentified parafoveal word do not influence the processing of that word on the subsequent fixation during reading. Moreover, the use of bilingual readers allows a much more powerful test of whether semantic codes can be integrated, because translations of words have virtually identical meanings but nonidentical orthographic and phonological representations.

\section{REFERENCES}

Altarriba, J., Kroll, J. F., Sholl, A., \& Rayner, K. (1996). The influence of lexical and conceptual constraints on reading mixedlanguage sentences: Evidence from eye fixations and naming times. Memory \& Cognition, 24, 477-492.

Altarriba, J., \& Mathis, K. M. (1997). Conceptual and lexical development in second language acquisition. Journal of Memory \& Language, 36, 550-568.

Altarriba, J., \& Soltano, E. G. (1996). Repetition blindness and bilingual memory: Token individuation for translation equivalents. Memory \& Cognition, 24, 700-711.

Balota, D. A. (1983). Automatic semantic activation and episodic memory encoding. Journal of Verbal Learning \& Verbal Behavior, 22, 88-104.

Balota, D. A., Pollatsek, A., \& Rayner, K. (1985). The interaction of contextual constraints and parafoveal visual information in reading. Cognitive Psychology, 17, 364-390.

Balota, D. A., \& RAYNer, K. (1983). Parafoveal visual information and semantic contextual constraints. Journal of Experimental Psychology: Human Perception \& Performance, 9, 726-738.

Binder, K. S., Pollatsek, A., \& Rayner, K. (1999). Extraction of information to the left of the fixated word in reading. Journal of Experimental Psychology: Human Perception \& Performance, 25, 1162-1172.

Bowers, J. S. (1999). Priming is not all bias: Commentary on Ratcliff and McKoon (1997). Psychological Review, 106, 582-596.

Brown, T. L., Roos-Glibert, L., \& CARr, T. H. (1995). Automaticity and word perception: Evidence from Stroop and Stroop dilution effects. Journal of Experimental Psychology: Learning, Memory, \& Cognition, 21, 1395-1411.

Caramazza, A., \& Brones, I. (1980). Semantic classifcation by bilinguals. Canadian Journal of Psychology, 34, 77-81.

Carr, T. H., McCauley, C., Sperber, R. D., \& Parmelee, C. M. (1982). Words, pictures and priming: On semantic activation and the automaticity of information processing. Journal of Experimental Psychology: Human Perception \& Performance, 8, 757-777.

Cristoffanini, P., Kirsner, K., \& Milech, D. (1986). Bilingual lexical representation: The status of Spanish-English cognates. Quarterly Journal of Experimental Psychology, 38A, 367-393.

De Groot, A. M. B., \& NAs, G. L. (1991). Lexical representation of cognates and noncognates in compound bilinguals. Journal of Memory \& Language, 30, 90-123.

Di Pace, E., Longoni, A. M., \& Zoccolotti, P. (1991). Semantic processing of unattended parafoveal words. Acta Psychologica, 77, 21-34.

EhrLich, S. F., \& RAYNER, K. (1981). Contextual effects on word perception and eye movements during reading. Journal of Verbal Learning \& Verbal Behavior, 20, 641-655.

Fuentes, L. J., \& Tudela, P. (1992). Semantic processing of foveally and parafoveally presented words in a lexical decision task. Quarterly Journal of Experimental Psychology, 45A, 299-322.

Gerhand, S. J., Deregowski, J. B., \& McAllister, H. (1995). Stroop phenomenon as a measure of cognitive functioning of bilingual (Gaelic/English) subjects. British Journal of Psychology, 86, 89-92.

Henderson, J. M., Dixon, P., Petersen, A., Twilley, L. C., \& FerREIRA, F. (1995). Evidence for the use of phonological representations during transsaccadic word recognition. Journal of Experimental Psychology: Human Perception \& Performance, 21, 82-97.

Henderson, J. M., \& Ferreira, F. (1990). Effects of foveal processing difficulty on the perceptual span in reading: Implications for attention and eye movement control. Journal of Experimental Psychology: Learning, Memory, \& Cognition, 16, 417-429. 
Henderson, J. M., \& Ferreira, F. (1993). Eye movement control during reading: Fixation measures reflect foveal but not parafoveal processing difficulty. Canadian Journal of Experimental Psychology, 47, 201-221.

InHoff, A. W. (1982). Parafoveal word perception: A further case against semantic preprocessing. Journal of Experimental Psychology: Human Perception \& Performance, 8, 137-145.

INHOFF, A. W. (1989). Lexical access during eye fixations in reading: Are word codes used to integrate lexical information across interword fixations? Journal of Memory \& Language, 28, 444-461.

InHoff, A. W., Brirhl, D., \& Schwart Z, J. (1996). Compound word effects differ in reading, on-line naming, and delayed naming tasks. Memory \& Cognition, 24, 466-476.

InHOFF, A. W., \& RAYNER, K. (1980). Parafoveal word perception: A case against semantic preprocessing. Perception \& Psychophysics, 27, 457-464.

INHOFF, A. W., STARr, M., \& SHINDLER, K. L. (2000). Is the processing of words during eye fixations in reading strictly serial? Perception \& Psychophysics, 62, 1474-1484.

Jordan, T. R., Patching, G. R., \& Milner, D. A. (1998). Central fixations are inadequately controlled by instructions alone: Implications for studying cerebral asymmetries. Quarterly Journal of Experimental Psychology, 51A, 371-391.

KenNedy, A. (1998). The influence of parafoveal words on foveal inspection time: Evidence for a processing tradeoff. In G. Underwood (Ed.), Eye guidance in reading and scene perception (pp. 149-180). New York: Elsevier.

Kennedy, A. (2000). Parafoveal processing in word recognition. Quarterly Journal of Experimental Psychology, 53A, 429-455.

Kennison, S. M., \& Clifton, C. (1995). Determinants of parafoveal preview benefit in high and low span working memory capacity readers: Implications for eye movement control. Journal of Experimental Psychology: Learning, Memory, \& Cognition, 21, 68-81.

Lambert, A. J., \& Sumich, A. L. (1996). Spatial orienting controlled without awareness: A semantically based implicit learning effect. Quarterly Journal of Experimental Psychology, 49A, 490-518.

Lee, H.-W., Rayner, K., \& Pollatsek, A. (1999). The time course of phonological, semantic, and orthographic coding in reading: Evidence from the fast-priming technique. Psychonomic Bulletin \& Review, 6, 624-634.

LiMA, S. D. (1987). Morphological analysis in sentence reading. Journal of Memory \& Language, 26, 84-99.

Marcel, A. J. (1983). Conscious and unconscious perceptions: Experiments on visual masking. Cognitive Psychology, 15, 197-237.

McClelland, J. L., \& Rumelhart, D. E. (1981). An interactive activation model of context effects in letter perception: Part 1. An account of basic findings. Psychological Review, 88, 375-407.

McConkie, G. W., \& Rayner, K. (1975). The span of the effective stimulus during a fixation in reading. Perception \& Psychophysics, 17, 578-586.

McConkIE, G. W., \& ZoLA, D. (1979). Is visual information integrated across successive fixations in reading? Perception \& Psychophysics, 25, 221-224.

MonSELL, S. (1991). The nature and locus of word frequency effects in reading. In D. Besner \& G. W. Humphreys (Eds.), Basic processes in reading (pp. 148-197). Hillsdale, $\mathrm{NJ}$ : Erlbaum.

NeELY, J. H. (1991). Semantic priming effects in visual word recognition: A selective review of current findings and theories. In D. Besner \& G. W. Humphreys (Eds.), Basic processes in reading (pp. 264336). Hillsdale, NJ: Erlbaum.

O'Regan, [J.] K. (1979). Saccade size control in reading: Evidence for the linguistic control hypothesis. Perception \& Psychophysics, 25, 501-509.

O'Regan, J. K. (1980). The control of saccade size and fixation duration in reading: The limits of linguistic control. Perception \& Psychophysics, 28, 112-117.

PAAP, K. R, \& Newsome, S. L. (1981). Parafoveal information is not sufficient to produce semantic or visual priming. Perception \& Psychophysics, 29, 457-466.

Patching, G. R., \& Jordan, T. R. (1998). Increasing the benefits of eye-tracking devices in divided visual field studies of cerebral asymmetry. Behavior Research Methods, Instruments, \& Computers, 30, 643-650.

Perea, M., \& Pollatsek, A. (1998). The effects of neighborhood frequency in reading and lexical decision. Journal of Experimental Psychology: Human Perception \& Performance, 24, 767-779.

Pollatsek, A., Lesch, M., Morris, R. K., \& Rayner, K. (1992). Phonological codes are used in integrating information across saccades in word identification and reading. Journal of Experimental Psychology: Human Perception \& Performance, 18, 148-162.

Pollatsek, A., Perea, M., \& Binder, K. S. (1999). The effects of neighborhood size in reading and lexical decision. Journal of Experimental Psychology: Human Perception \& Performance, 25, 11421158.

Pollatsek, A., TAN, L.-H., \& RAYner, K. (2000). The role of phonological codes in integrating information across saccadic eye movements in Chinese character identification. Journal of Experimental Psychology: Human Perception \& Performance, 26, 607-633.

RAYNER, K. (1975). The perceptual span and peripheral cues in reading. Cognitive Psychology, 7, 65-81.

RAYNER, K. (1978). Foveal and parafoveal cues in reading. In J. Requin (Ed.), Attention and performance VII (pp. 149-162). Hillsdale, NJ: Erlbaum.

RAYNER, K. (1998). Eye movements in reading and information processing: 20 years of research. Psychological Bulletin, 124, 372-422.

Rayner, K., Balota, D. A., \& Pollatsek, A. (1986). Against parafoveal semantic preprocessing during eye fixations in reading. Canadian Journal of Psychology, 40, 473-483.

Rayner, K., Fischer, M. H., \& Pollatsek, A. (1998). Unspaced text interferes with both word identification and eye movement control. Vision Research, 38, 1129-1144.

Rayner, K., McConkie, G. W., \& Ehrlich, S. F. (1978). Eye movements and integrating information across fixations. Journal of Experimental Psychology: Human Perception \& Performance, 4, 529-544.

RAYNer, K., McConkie, G. W., \& Zola, D. (1980). Integrating information across eye movements. Cognitive Psychology, 12, 206-226.

Rayner, K., \& Pollatsek, A. (1989). The psychology of reading. Englewood Cliffs, NJ: Prentice Hall.

RAYNER, K., \& Well, A. D. (1996). Effects of contextual constraint on eye movements in reading: A further examination. Psychonomic Bulletin \& Review, 3, 504-509.

Rayner, K., Well, A. D., Pollatsek, A., \& Bertera, J. H. (1982). The availability of useful information to the right of fixation in reading. Perception \& Psychophysics, 31, 537-550.

Reichle, E. D., Pollatsek, A., Fisher, D. L., \& Rayner, K. (1998). Towards a model of eye movement control in reading. Psychological Review, 105, 125-157.

Schroyens, W., Vitu, F., Brysbaert, M., \& D'Ydewalle, G. (1999). Eye movement control during reading: Foveal load and parafoveal processing. Quarterly Journal of Experimental Psychology, 52A, $1021-1046$

Schustack, M. W., Ehrlich, S. F., \& Rayner, K. (1987). The complexity of contextual facilitation in reading: Local and global influences. Journal of Memory \& Language, 26, 322-340.

Sereno, S. C. (1995). The resolution of lexical ambiguity: Evidence from an eye movement priming paradigm. Journal of Experimental Psychology: Learning, Memory, \& Cognition, 21, 285-294.

Sereno, S. C., \& RAYNER, K. (1992). Fast priming during eye fixations in reading. Journal of Experimental Psychology: Human Perception \& Performance, 18, 173-184.

SERENo, S. C., \& RAYNER, K. (2000). Spelling-sound regularity effects on eye fixations in reading. Perception \& Psychophysics, 62, 402409.

Stanners, R. F., Neiser, J. J., Hernon, W. P., \& Hall, R. (1979). Memory representation for morphologically related words. Journal of Verbal Learning \& Verbal Behavior, 18, 733-743.

Thomas, M. S. C., \& Allport, A. (2000). Language switching costs in bilingual word recognition. Journal of Memory \& Language, 43, 4466.

Tzelgov, J., Henik, A., \& Leiser, D. (1990). Controlling Stroop in- 
terference: Evidence from a bilingual task. Journal of Experimental Psychology: Learning, Memory, \& Cognition, 16, 760-771.

UNDERWOOD, G. (1985). Eye movements during the comprehension of written language. In A. W. Ellis (Ed.), Progress in the psychology of language (Vol. 2, pp. 45-71). London: Erlbaum.

VITU, F. (1991). The influence of parafoveal preprocessing and linguistic context on the optimal landing position effect. Perception \& Psychophysics, 50, 58-75.

Zola, D. (1984). Redundancy and word perception during reading. Perception \& Psychophysics, 36, 277-284.

\section{NOTES}

1. Note that we are not claiming that all patterns of data are the same in reading and naming (see Inhoff, Briihl, \& Schwartz, 1996, for one clear counterexample). We are merely claiming that (so far) the pattern of preview benefit (perhaps representing only early processing stages) appears to be the same in the two tasks.

2. For examples of studies showing no parafoveal semantic processing, see Inhoff (1982), Inhoff and Rayner (1980), and Paap and Newsome (1981).

3. Other recent studies (Inhoff, Starr, \& Shindler, 2000; Kennedy, $1998,2000)$ examining the effects of parafoveal information on processing have demonstrated that the duration of a fixation in reading can be influenced by the word immediately to the right of the fixated word. However, these effects seem to be related to the orthographic structure of the parafoveal word and not due to lexical/semantic processing. For example, the frequency of the word to the right of fixation does not affect the duration of the current fixation (Henderson \& Ferreira, 1993; Rayner, Fischer, \& Pollatsek, 1998).

4. Only 18 cognates were used (as opposed to 36 noncognates) because of the difficulty in finding cognates that were matched on word length.

5. Our reason for choosing the $2^{\circ}$ location for the preview is that it approximates the distance that subjects typically move their eyes in reading. In prior pilot work, we found that if the preview word is presented $2^{\circ}$ from fixation and then the screen goes blank when the saccade begins, subjects can identify the preview word about $50 \%$ of the time. However, if the preview word is replaced by the target word, as in the present experiment, but the subjects are asked to identify the preview word (rather than the target word), they are unable to successfully identify it (i.e., they are accurate less than $1 \%$ of the time).

6 . The analyses in this paragraph compared the data of the monolinguals with the averages over Spanish and English targets for the bilinguals. The analyses comparing the monolinguals with the bilinguals when using only the English targets were less powerful. The difference between the identical and translation conditions across groups was not significant $\left[F_{1}(1,34)=1.43 ; F_{2}(1,52)=1.46, p s>.20\right]$, the monolinguals were significantly faster than the bilinguals $\left[F_{1}(1,34)=9.14, p<\right.$ $\left..001 ; F_{2}(1,52)=6.13, p<.001\right]$, and the bigger difference between the identical and control preview conditions for the monolinguals was only marginally significant by subjects $\left[F_{1}(1,34)=3.05, p=.09 ; F_{2}(1,52)=\right.$ $4.13, p<.05]$

7. The items analyses here (and throughout Experiment 2) assume a matched items design, in which the Spanish and English versions of a target word are assumed to be matched. Since they are embedded in different sentence frames, a case could be made for not treating them as matched. Because the analyses using an independent group analysis came out quite similarly, we will present only the matched analyses.

8. A formal power calculation would only yield a more pessimistic conclusion. That is, if the effect size were estimated to be $11 \mathrm{msec}$ and the true $S E$ for 54 subjects is $11 \mathrm{msec}$, then a sample size of 567 would be needed if one wanted to set $\alpha$ equal to .05 and $\beta$ equal to .10 .

9 . The pattern was reasonably similar for first-fixation durations. The means for the first three contrasts were 5,4 , and $5 \mathrm{msec}$, and the medians are $3,-2$, and $5 \mathrm{msec}$, respectively. Thus, with the possible exception of contrast 3 , there appears to be little reason to think that there was any difference in patterns between the cognates and pseudocognates.

10. Kennison and Clifton (1995) did examine the effect of memory span on preview benefit, and found that low-and high-span readers did not differ in the amount of preview benefit they obtained from a parafoveal word.

11. In fact, we think it is likely that we would have lost a majority of our subjects because they would have found the task too frustrating.

(Manuscript received February 2, 2000; revision accepted for publication July 25,2000 .) 